\title{
Nutrition and nutraceuticals in the changing management of osteoarthritis for dogs and cats
}

\author{
Karie A. Johnson DVM \\ Anne H. Lee MS \\ Kelly S. Swanson $\mathrm{PhD}$
}

\begin{abstract}
From the Department of Animal Sciences, College of Agricultural, Consumer and Environmental Sciences, University of Illinois, Urbana, IL 6I80I. Dr. Johnson's present address is VIP Vet Visit, Orland Park, IL 60462.

Address correspondence to Dr. Swanson (ksswanso@illinois.edu).
\end{abstract}

O steoarthritis is a progressively painful disease characterized by articular cartilage degradation with loss of proteoglycan and collagen, subchondral bone sclerosis, periarticular proliferation of new bone, and chronic inflammation of synovial membranes. ${ }^{1}$ Osteoarthritis is estimated to affect approximately $20 \%$ of dogs $\geq 1$ year of age and $90 \%$ of dogs $>5$ years of age. ${ }^{2-5}$ Cats are similarly affected by osteoarthritis, with prevalences ranging from $16.5 \%$ to $91 \%$ and increasing with age. $^{6-9}$ Given the high prevalences reported, it is possible that companion animals may have undiagnosed osteoarthritis and the associated pain that goes unnoticed. Cats in particular may not show clinical signs typically associated with osteoarthritis, and even subtle changes in a cat's behavior at home may be caused by osteoarthritis-associated pain. Veterinarians should closely evaluate patients' joints at every annual examination and discuss signs of osteoarthritis and pain with clients. To prevent disease progression as early as possible, discussions about osteoarthritis should take place for patients as young as 1 year of age. Careful evaluation and client education are essential to identifying osteoarthritis in its earliest stages.

Clinical signs of osteoarthritis include evidence of pain or tenderness, decreased range of motion, swelling, stiffness, muscle atrophy, crepitus, and effusion. The presence of pain can cause an animal's behavior to change, leading to aggression or decreased activity, in addition to signs such as limping and difficulty rising, climbing stairs, or getting onto furniture. ${ }^{10}$ Painful disease makes it difficult for pets to interact with people, which strains the human-animal bond and can damage the relationship with the owner. Because of osteoarthritis-related pain, pets may have trouble walking around the home. They

\section{ABBREVIATIONS}

$\begin{array}{ll}\text { BCS } & \text { Body condition score } \\ \text { DHA } & \text { Docosahexaenoic acid } \\ \text { EPA } & \text { Eicosapentaenoic acid } \\ \text { GLM } & \text { Green-lipped mussel }\end{array}$

may avoid hardwood, tile, or other slippery surfaces. Owners who notice their pet struggling may add rugs or carpets to these surfaces to support the pet's mobility. The effects of osteoarthritis can be debilitating, especially when owners are not aware of the necessary accommodations. Whereas it has been shown that osteoarthritis may lead to earlier euthanasia, veterinarians can improve a patient's quality of life and potentially extend its longevity through greater preventative care and multimodal management approaches. $^{11}$

Osteoarthritis is a long-term disease, and its management in pets is challenging for veterinarians and pet owners. Treatment can be costly and frustrating. It takes patience and persistence to identify the most appropriate combination of interventions that may be used for the remainder of a pet's life. Options include medications such as NSAIDs and opioids, nutraceuticals, physical rehabilitation, weight loss, and complete and balanced therapeutic diets. Nutritional intervention, especially control of caloric intake, has been shown to be an environmental factor that veterinarians and owners can use to delay or control osteoarthritis in pets. ${ }^{12}$ Veterinarians and owners should discuss nutrition and healthy body condition, including the use of therapeutic diets, as part of a pet's overall health and well-being. Pain caused by osteoarthritis may be controlled with medications; these provide a temporary solution, as they decrease signs of pain but do not treat underlying problems within joints or modify disease progression. ${ }^{13}$ Nutritional management, including the feeding of therapeutic diets formulated for joint health, dietary supplementation with selected nutraceuticals, and facilitation of weight loss when needed, may help to prevent or slow the progression of osteoarthritis. , $^{3,11,13-23}$

\section{Risk Factors for Osteoarthritis}

Several genetic and environmental factors may increase cartilage damage and promote degenerative 
changes to joints. Larger-breed dogs are commonly thought to develop osteoarthritis at an earlier age, with more severe clinical signs than smaller breeds. ${ }^{24}$ In a records-based study 25 of 148,741 dogs from 93 clinics across England, researchers found that some purebred dogs had a higher prevalence of degenerative joint disease than others, suggesting inherited genetic defects in particular breeds. Other study ${ }^{26,27}$ results indicate that Labrador Retrievers in particular have risks for hip dysplasia, elbow dysplasia, and cranial cruciate ligament rupture that are 3.4, 20.5, and 5.5 times those for mixed-breed dogs.

Other factors such as the age and sex of an animal also play roles in the development of osteoarthritis. Although osteoarthritis can develop at any age, its higher prevalence in older dogs indicates that it is a disease associated with aging. It is often a result of long-term wear and impact on joints, with higher prevalence and frequency of diagnosis in older dogs when mobility is affected and obvious clinical signs are observed. Less information is available for cats, but studies have shown that $16.5 \%$ to $91 \%$ of cats (prevalence increasing with age) have radiographic evidence of osteoarthritis even when clinical signs are not observed. ${ }^{7-9}$ Although the exact mechanisms by which age affects the development of osteoarthritis are unknown, it is likely related to a combination of changes in the capacity of joint tissues to adapt to biomechanical damage. ${ }^{28}$

The sex of animals also has been associated with osteoarthritis risk, with male dogs having a greater risk of developing hip joint osteoarthritis than females. ${ }^{29}$ In people, sex hormones (gonadal steroid hormones) modulate the joint tissues during tissue development and throughout the life cycle. ${ }^{30}$ Although there is little evidence available on the means by which sex hormones influence the joint tissues of dogs, it has been shown that chondrocytes have unique responses to sex hormones owing to differing actions of the hormones and receptor numbers in people. ${ }^{30}$

Although many factors may contribute, the increasing incidence of osteoarthritis may be linked with obesity in dogs. ${ }^{31,32}$ Obesity and overweight status in dogs have been defined as body weights that are $20 \%$ and $10 \%$ greater than the ideal weight, respectively. ${ }^{33,34}$ Obesity is a common problem, affecting an estimated $59.5 \%$ of cats and $55.8 \%$ of dogs in the United States. ${ }^{35}$ It has also been defined as having sufficient excess body fat to cause or contribute to disease..$^{14}$ The long-term stress exerted on joints by excess body weight has been associated with loss of articular cartilage in people and dogs..$^{15,36}$ In addition, obesity has been associated with increased oxidative stress and inflammation, which can cause cellular injury and tissue damage. ${ }^{14}$ The reported high prevalence of obesity, particularly in mature patients, and the high frequency of osteoarthritis in dogs and cats emphasize the importance that veterinarians should place on educating owners about proper pet nutrition and healthy weight status.
Proper nutrition enhances the duration and quality of a pet's life, which is why nutrition should be discussed during every examination, and examinations should include measurement of body weight and assessment of BCS. A BCS is used to evaluate body fat, with a score of 4 or 5 out of 9 considered ideal according to the American Animal Hospital Association guidelines for nutritional assessment of dogs and cats. ${ }^{37}$ Pets with a BCS of 4 to 5 may appear to be too thin to some owners, as the number of overweight and obese pets continues to increase and overweight pets have become more common. ${ }^{37}$ According to the 9-point scale, each 1-unit change in BCS is equivalent to a change in body fat of approximately $5 \% .{ }^{38,39}$ The net effect of excessive body weight is increased mechanical stress on joints and an inflammatory state, promoting degeneration and often leading to osteoarthritis. ${ }^{40}$

Lifelong investigations ${ }^{41,42}$ of 48 Labrador Retrievers showed that even moderately overweight dogs were at greater risk for earlier morbidity and reduced median life span, compared with lean dogs. Mean body weight of dogs in the control-fed group of that study ( $\mathrm{n}=24$ ) was $26 \%$ greater, and the median life span of that group was $15 \%$ (1.8 years) shorter, compared with findings for dogs (24) that had restricted dietary intake (dogs fed 25\% less of the same food provided to the control-fed group); the control-fed group also required medications to treat signs of osteoarthritis a mean of 3 years sooner than the group that had restricted intake. ${ }^{41,42} \mathrm{~A}$ reduction in caloric intake to maintain a healthy body weight can also delay the onset and decrease the severity of hip joint laxity and osteoarthritis in dogs. ${ }^{16,43}$ Controlling an animal's weight minimizes abnormal forces placed on joints, preventing or delaying the onset of osteoarthritis and helping to alleviate signs of disease..$^{14}$ Among obese dogs with hip or elbow joint osteoarthritis, even moderate body weight loss was found to be beneficial, with approximately $6 \%$ weight loss associated with a decrease in subjective measures of lameness and approximately $9 \%$ weight loss associated with a decrease in objective measures of lameness. ${ }^{33}$

\section{Weight Loss}

As previously discussed, obese dogs and cats (ie, those with BCS $\geq 7 / 9$ ) are more prone to inflammatory conditions and development of osteoarthritis

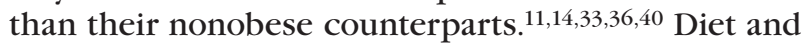
exercise are important, but successful weight loss for a pet requires a long-term commitment by the owner. When changing a patient's diet, it is important to consider not only the type of diet fed (eg, a therapeutic weight loss diet, over-the-counter low-calorie diet [also described as a light diet], or over-the-counter diet formulated to maintain healthy weight), but also patient preferences and owner constraints. Diets formulated for weight loss often contain a higher protein concentration than typical commercial diets and may contain L-carnitine, with both ingredients help- 
ing to maintain lean body mass and muscle strength while promoting fat loss. Such diets are designed to have higher nutrient-to-calorie ratios to avoid overrestriction of essential nutrients such as vitamins and minerals. ${ }^{6,44}$ Increased protein and fiber contents are complementary in providing enhanced satiety, which reduces begging and other undesirable pet behaviors that can contribute to owner noncompliance. ${ }^{6,14,44}$

An increase in the water content of foods may also decrease calorie intake and aid in weight loss. ${ }^{6}$ This is especially useful for smaller dogs and cats because feeding a wet diet is easier to accomplish. Owners may overfeed dry foods because of the small volume required to meet the caloric needs. Recommended amounts of these energy- and nutrient-dense foods may be perceived to be insufficient, especially if large food bowls are used, as it has been shown that use of a smaller food bowl helps to decrease the amount fed by owners, thus decreasing food in take by up to $10 \% .^{6, a}$ Because the density of kibble (in terms of calories and weight) may vary greatly, owners should be encouraged to weigh their pet's food and allocate it in grams rather than measuring it on the basis of volume (ie, in cups or scoops). If this is not possible or the owner is reluctant to use such an approach, use of a smaller bowl and food scoop may be helpful for achieving weight loss and longterm weight control for pets, owing to influences on owner perception. ${ }^{6}$ Veterinarians should provide assistance so that owners can determine the easiest ways to decrease their pet's calorie consumption to help optimize health, while maintaining satiety and keeping the owner happy with the management plan.

When creating a weight loss plan, it is important to educate clients on setting small goals and maintaining a consistent effort. A loss of $1 \%$ to $2 \%$ of body weight/wk is the typical goal until a desired maintenance weight is reached. ${ }^{14}$ The consistency required to observe results can be extremely difficult for owners to attain. If owners consider it unreasonable to stop giving treats, these must be incorporated into the plan. Noncompliance may be addressed by encouraging owners to indulge their pet according to healthy guidelines. Owners can be educated about alternative reward options to help them adhere to a weight loss plan. Limiting treats and snacks to $<10 \%$ of the pet's total caloric intake and providing healthy treat options are important components. Low-calorie treats for dogs and cats may include carrots ( 1 baby carrot provides approx $5 \mathrm{kcal}$ ), green beans (1 cup supplies approx $30 \mathrm{kcal}$ ), air-popped popcorn (1 cup supplies approx $30 \mathrm{kcal}$ ), tuna ( 2 ounces supplies approx $50 \mathrm{kcal}$ ), strawberries (1 cup provides approx 50 kcal), or blueberries (one-fourth cup provides approx 20 kcal). Even low-calorie options such as miniature marshmallows at approximately $50 \mathrm{kcal} /$ one-third cup can provide owners with a treat option meant to spoil their pet while staying on track for their pet's weight loss. ${ }^{45}$ Dividing the daily food allotment into multiple small meals lowers the potential for begging behavior, which can also help owners comply with the plan. Regular check-ins and counseling are good ways to monitor progress, provide advice and encouragement, and give owners a sense of accomplishment as their pet's weight approaches the goal.

Along with dietary adjustments, increased exercise is also important for any successful weight loss plan. ${ }^{46}$ The combination of caloric restriction and intensive physical activity is more efficient in facilitating weight loss than dietary management alone. An added benefit of this combination is improved mobility in patients. ${ }^{47}$ Increased mobility leads to a consistent level of moderate activity, which is important for joint health, especially in patients with osteoarthritis. ${ }^{48}$ Some of the most effective activities for improved mobility include leash walking, walking in water, and swimming. ${ }^{48}$ It is also important for owners to support their pet's mobility by use of throw rugs or nonslip mats, supportive bedding, and ramps. ${ }^{48}$ These items allow the pet to ambulate independently and maintain their exercise or activity levels even in the presence of joint pain. Allowing a pet to have free range throughout the home as it normally would can also help maintain interactions with owners and preserve the human-animal bond.

\section{Osteoarthritis Management With NSAIDs and Multimodal Therapy}

There are many treatment options for dogs and cats with osteoarthritis. These most commonly include surgery, pharmacological treatment, physical rehabilitation, weight management, and dietary supplementation with nutraceuticals. Management options should be carefully selected according to the severity and progression of the disease. A multimodal approach may be used to alleviate pain and slow disease progression. Nonsteroidal anti-inflammatory drugs are the most commonly used pharmacological agents for pain management. Despite their effectiveness for reducing osteoarthritis-associated pain, NSAIDs and corticosteroids may accelerate cartilage degeneration with long-term use. ${ }^{49}$ In addition, there have been reports of adverse reactions affecting the gastrointestinal tract (eg, duodenal ulcers), renal system (eg, acute renal failure), and liver (eg, increased enzyme activities) in dogs undergoing short-term and long-term NSAID administration. ${ }^{49}$ The knowledge that long-term NSAID administration can cause cartilage damage raises a concern about prescribing these drugs for young adult dogs with hip joint osteoarthritis. Patients with osteoarthritis are usually prescribed daily pain medications for many years, creating a fundamentally flawed treatment plan; although the treatment relieves clinical signs associated with pain and inflammation, the underlying problem continues to worsen. Ideally, a management plan that reduces the signs of osteoarthritis without increasing the risk for long-term joint or organ damage should be sought. 
Pain management is an important aspect of patient care, but it is best if medications are provided as secondary therapy. A treatment plan should be aimed at slowing the progression of osteoarthritis with the goal of providing patients with a longer life span. The adverse effects of NSAIDs, especially on the cartilage, may be mitigated or possibly prevented by prescribing their short-term or daily administration at the lowest effective dose calculated on the basis of the animal's ideal body weight. Foods and dietary supplements formulated for joint health have anti-inflammatory and chondroprotective effects ${ }^{17}$ with potential minor adverse effects (eg, diarrhea), unlike
NSAIDs that can be associated with adverse reactions without improving the underlying joint disease. ${ }^{13}$ Common ingredients incorporated into therapeutic diets formulated for joint health include omega-3 fatty acids, GLM, glucosamine, and chondroitin sulfate. Results of several studies ${ }^{1,3,4,10,18-21,23}$ support that these ingredients are beneficial in the management of osteoarthritis, particularly in dogs since research involving cats is more limited (Table I). The combination of chondroitin sulfate, glucosamine, and omega-3 fatty acids has also been shown to improve the joint status of search-and-rescue dogs as assessed by subjective means. ${ }^{31}$

Table I-Examples of nutritional and nutraceutical strategies associated with improvement in clinical signs for dogs with osteoarthritis.

\begin{tabular}{|c|c|c|c|c|c|}
\hline $\begin{array}{l}\text { Study design } \\
\text { (treatment duration) }\end{array}$ & Animals & Intervention & Control & Main outcomes & Referenc \\
\hline $\begin{array}{l}\text { Prospective, randomized, blinded } \\
\text { clinical trial }(90 \mathrm{~d})\end{array}$ & $\begin{array}{l}\text { Client-owned dogs } \\
\text { with chronic } \\
\text { osteoarthritis of hip } \\
\text { or stifle joints }(n=177)\end{array}$ & $\begin{array}{l}\text { Diet A: } 0.8 \% \text { EPA-DHA }(n=55) \\
\text { Diet B: } 2 \% \text { EPA-DHA }(n=62) \\
\text { Diet C: } 2.9 \% \text { EPA-DHA }(n=60)\end{array}$ & NA & $\begin{array}{l}\text { Significant improvements in lameness, } \\
\text { weight bearing, clinical signs of arthritis } \\
\text { progression, and overall condition for dogs } \\
\text { fed diet C, compared with dogs fed diet A }\end{array}$ & \\
\hline $\begin{array}{l}\text { Randomized, double-blinded, } \\
\text { controlled clinical trial ( } 6 \text { mo) }\end{array}$ & $\begin{array}{l}\text { Client-owned dogs with } \\
\text { osteoarthritis in } \\
\geq 1 \text { joint }(n=127)\end{array}$ & $\begin{array}{l}\text { Test diet: } 3.47 \% \text { omega- } 3 \text { fatty } \\
\text { acids }(n=7 I)\end{array}$ & $\begin{array}{l}\text { Control diet: commercial } \\
\text { adult dog food containing } \\
0.11 \% \text { omega- } 3 \text { fatty acids } \\
(n=56)\end{array}$ & $\begin{array}{l}\text { Dogs fed the test diet had significantly } \\
\text { increased ability to rise from rest and } \\
\text { play at } 6 \mathrm{wk} \text { and ability to walk at } 12 \\
\text { and } 24 \mathrm{wk} \text {, compared with dogs that } \\
\text { received the control diet }\end{array}$ & \\
\hline $\begin{array}{l}\text { Randomized, controlled } \\
\text { clinical trial (12 wk) }\end{array}$ & $\begin{array}{l}\text { Dogs with chronic } \\
\text { osteoarthritis }(n=109) \\
\text { receiving a standardized } \\
\text { carprofen dose (approx } \\
4.4 \mathrm{mg} / \mathrm{kg}, \mathrm{PO}, \mathrm{q} 24 \mathrm{~h}) \\
\text { at the start of the study }\end{array}$ & $\begin{array}{l}\text { Fish oil-enriched therapeutic diet: } \\
3.5 \% \text { omega- } 3 \text { fatty acids }(n=52)\end{array}$ & $\begin{array}{l}\text { Control diet: commercial } \\
\text { adult dog food containing } \\
0.1 \% \text { omega- } 3 \text { fatty acids } \\
(n=57)\end{array}$ & $\begin{array}{l}\text { Carprofen dose was decreased (on the } \\
\text { basis of investigator and owner assessments) } \\
\text { significantly earlier for dogs fed the fish } \\
\text { oil-enriched diet than for dogs fed the control } \\
\text { diet }\end{array}$ & \\
\hline $\begin{array}{l}\text { Randomized, double-blinded, } \\
\text { controlled clinical trial (90 d) }\end{array}$ & $\begin{array}{l}\text { Client-owned dogs with } \\
\text { osteoarthritis }(n=38)\end{array}$ & $\begin{array}{l}\text { Test diet: } 3.5 \% \text { omega- } 3 \text { fatty } \\
\text { acids }(n=22)\end{array}$ & $\begin{array}{l}\text { Control diet (commercial } \\
\text { adult dog food): } 0.11 \% \\
\text { omega-3 fatty acids }(n=16)\end{array}$ & $\begin{array}{l}\text { Dogs fed the test diet had a significantly greater } \\
\text { increase in peak vertical force in affected limbs } \\
\text { from baseline, compared with results for dogs } \\
\text { fed the control diet }\end{array}$ & \\
\hline $\begin{array}{l}\text { Randomized, controlled, } \\
\text { double-blinded clinical trial } \\
\text { (I3 wk) }\end{array}$ & $\begin{array}{l}\text { Privately owned dogs } \\
\text { with hip or stifle joint } \\
\text { osteoarthritis }(n=30)\end{array}$ & $\begin{array}{l}\text { Therapeutic diet: } 1.08 \% \text { omega- } 3 \\
\text { fatty acids }(n=15)\end{array}$ & $\begin{array}{l}\text { Control diet: } 0.07 \% \text { omega- } 3 \\
\text { fatty acids }(n=15)\end{array}$ & $\begin{array}{l}\text { Dogs fed the therapeutic diet had significantly } \\
\text { greater peak vertical force in affected limbs } \\
\text { during weeks } 7 \text { and } 13 \text { than dogs fed the control } \\
\text { diet }\end{array}$ & \\
\hline $\begin{array}{l}\text { Double-blinded, placebo-controlled } \\
\text { clinical trial }(28 \mathrm{~d})^{*}\end{array}$ & $\begin{array}{l}\text { Client-owned dogs with } \\
\text { osteoarthritis }(n=59)\end{array}$ & $\begin{array}{l}\text { CFB low dose: } 69 \mathrm{mg}(n=14) \\
\text { CFB high dose: } 127 \mathrm{mg}(n=14) \\
\text { Combination treatment: } 69 \mathrm{mg} \\
\text { of CFB, } 500 \mathrm{mg} \text { of glucosamine } \\
\text { hydrochloride, and } 200 \mathrm{mg} \text { of } \\
\text { chondroitin sulfate }(n=16)\end{array}$ & $\begin{array}{l}\text { Placebo: } 60 \mathrm{mg} \text { of fructose } \\
(n=15)\end{array}$ & $\begin{array}{l}\text { Dogs in CFB low-dose and high-dose groups } \\
\text { had significantly improved ability to rise from } \\
\text { a lying position, compared with placebo group } \\
\text { dogs }\end{array}$ & \\
\hline $\begin{array}{l}\text { Randomized, double-blinded, } \\
\text { positive-controlled clinical } \\
\text { trial (70 d)* }\end{array}$ & $\begin{array}{l}\text { Privately owned dogs } \\
\text { with hip or elbow joint } \\
\text { osteoarthritis }(n=35)\end{array}$ & $\begin{array}{l}\text { Glucosamine hydrochloride } \\
(475 \mathrm{mg} / \mathrm{g}), \text { chondroitin } \\
\text { sulfate }(350 \mathrm{mg} / \mathrm{g}) \text {, } \\
\mathrm{N} \text {-acetyl-D-glucosamine } \\
(50 \mathrm{mg} / \mathrm{g}) \text {, ascorbic acid }(50 \mathrm{mg} / \mathrm{g}) \text {, } \\
\text { and } \mathrm{Zn} \text { sulfate }(30 \mathrm{mg} / \mathrm{g}) \text { in a gelatin } \\
\text { capsule: I g for dogs that weighed } \\
5 \text { - } 19.9 \mathrm{~kg}, 1.5 \mathrm{~g} \text { for dogs that } \\
\text { weighed } 20-39.9 \mathrm{~kg} \text {, and } 2 \mathrm{~g} \text { for } \\
\text { dogs that weighed }>40 \mathrm{~kg} \text {; products } \\
\text { given twice daily for } 42 \text { days, then } \\
\text { dose was reduced by one-third for } \\
28 \mathrm{~d}(\mathrm{n}=16)\end{array}$ & $\begin{array}{l}\text { Carprofen: } 2 \mathrm{mg} / \mathrm{kg}, \mathrm{PO} \text {, } \\
\text { twice daily for } 7 \text { days, } \\
\text { followed by } 2 \mathrm{mg} / \mathrm{kg}, \mathrm{PO} \text {, } \\
\text { once daily }(\mathrm{n}=19)\end{array}$ & $\begin{array}{l}\text { Dogs in the glucosamine-chondroitin group } \\
\text { had significantly improved veterinarian-assessed } \\
\text { scores for pain, weight bearing, and overall } \\
\text { condition by day } 70 \text {; dogs in the carprofen group } \\
\text { had significantly improved veterinarian-assessed } \\
\text { scores for lameness, joint mobility, pain, weight } \\
\text { bearing, and overall condition by day } 42\end{array}$ & \\
\hline Field trial $(50 \mathrm{~d}) \dagger$ & $\begin{array}{l}\text { Privately owned dogs } \\
\text { with osteoarthritis } \\
\text { (rated mild to } \\
\text { medium; } \mathrm{n}=85 \text { ) }\end{array}$ & $\begin{array}{l}\text { Nutritionally complete dog food } \\
\text { supplemented with } 0.3 \% \text { GLM } \\
(\mathrm{n}=85)\end{array}$ & $\begin{array}{l}\text { NA; data were compared } \\
\text { with pretreatment values } \\
\text { when each dog received } \\
\text { its routine diet }\end{array}$ & $\begin{array}{l}\text { Significant reductions in visual (mobility } \\
\text { impairment) scores, manipulation (clinical } \\
\text { signs on manipulation of joints) scores, and } \\
\text { total arthritic (visual plus manipulation) scores } \\
\text { on day } 50 \text { of the dietary treatment, compared } \\
\text { with pretreatment results }\end{array}$ & \\
\hline $\begin{array}{l}\text { Double-blinded, } \\
\text { longitudinal, } \\
\text { controlled clinical } \\
\text { trial }(90 \mathrm{~d}) \ddagger\end{array}$ & $\begin{array}{l}\text { Client-owned dogs } \\
\text { with osteoarthritis } \\
(n=23)\end{array}$ & $\begin{array}{l}\text { GLM-supplemented diet for } \\
60 \text { days }(n=23)\end{array}$ & $\begin{array}{l}\text { Control diet: } \\
\text { commercial adult } \\
\text { dog food for } 30 \text { days } \\
(n=23)\end{array}$ & $\begin{array}{l}\text { Peak vertical force significantly improved } \\
\text { during the GLM-supplemented diet phase, } \\
\text { compared with the control diet phase and } \\
\text { pretreatment value (day } 0 \text { ) }\end{array}$ & 2 \\
\hline
\end{tabular}

*Dogs were fed a commercial adult dog food during the study. $\nmid$ Dogs received the GLM-supplemented diet exclusively for 45 days after a 5 -day transition period in which they received their normal diet mixed with increasing amounts of the study food. $\ddagger$ All dogs received the control diet on days I to 30 and the GLM-supplemented diet on days 3 I to 90 of the 90 -day study.

CFB = Calcium fructoborate. NA = Not applicable.

To convert $\mathrm{mg} / \mathrm{kg}$ to $\mathrm{mg} / \mathrm{lb}$, divide by 2.2 . 


\section{Omega-3 Fatty Acids}

Omega-3 fatty acids, specifically EPA and DHA, are commonly used for the management of osteoarthritis-associated inflammation and pain. Omega-3 fatty acids decrease production of prostaglandin E2 in cartilage and compete with arachidonic acid as a substrate for cyclooxygenase and lipoxygenase enzymes, which are associated with pain and inflammation. ${ }^{17,50}$ These fatty acids also decrease production of thromboxane A2 and leukotriene B4, which suppresses proinflammatory mediators interleukin-1, interleukin-2, and tumor necrosis factor in cartilage. $3,6,17,48,50$ Omega-3 and omega- 6 fatty acids were shown to decrease pro-matrix metallopeptidase expression in synovial fluid by $37 \%$ and decrease total arachidonic acid concentrations in plasma by $30 \% .^{14,51}$ Overall, omega-3 fatty acids are thought to decrease inflammation throughout the body, including the joints, leading to a decrease in cellular injury and tissue damage. ${ }^{14,17,50,51}$ The effects of omega-3 fatty acids on joint pain are supported by improved weight-bearing scores and force plate analysis results for dogs with a diagnosis of osteoarthritis that received omega- 3 fatty acid supplements. ${ }^{19}$ Administration of omega- 3 fatty acids has been associated with improved overall weight-bearing ability; ability to rise from resting, play, and walk; and lameness scores for dogs and with increased activity, increased ability to jump, and decreased lameness scores for cats. $13,6,13,17,19,20$ The effects of omega-3 fatty acids on pain are also supported by findings that dogs receiving fish oil supplements had sufficient improvement to allow a decrease in or discontinuation of NSAID treatment (a finding reported for nearly half of the dogs [24/52] that received fish oil in 1 report $^{18}$ ) without any changes in signs of pain or joint stiffness. ${ }^{13,14,18}$

It is important to note, however, that providing omega-3 fatty acids by administration of fish oil supplements can be complicated and unpleasant for owners. The reported dose range of omega- 3 fatty acids is 230 to $370 \mathrm{mg}$ of EPA and DHA $/ \mathrm{kg}$ of body weight ${ }^{0.75}$ for dogs with osteoarthritis. ${ }^{17}$ It should be noted that the safe upper limit of EPA and DHA recommended by the National Research Council ${ }^{52}$ is $370 \mathrm{mg} / \mathrm{kg}$ of body weight ${ }^{0.75}$ for dogs, so that amount should not be exceeded. Compliance is also an issue, especially for owners of large- or giant-breed dogs that could require a large number of fish oil pills daily, depending on the omega- 3 fatty acid content provided. To avoid potential problems related to administration of fish oil pills, therapeutic diets may be prescribed. For example, dogs with osteoarthritis that were fed a diet enriched in omega-3 fatty acids (3.5\% fish oil) had significant improvements in the degree of lameness, ability to rise from a resting position, and ability to walk, compared with findings for dogs with the same condition that were fed a conventional diet. ${ }^{19}$ Such diets have been associated with improved short-term outcome measures for dogs with osteoarthritis in sev- eral studies (Table 1). Most diets designed to improve joint health have been formulated to contain the recommended amounts of omega- 3 fatty acids when fed according to the label, eliminating the need for pill administration. If a client is reluctant to change a pet's diet or has financial constraints, administration of fish oil supplements should be considered as part of the multimodal management for patients with osteoarthritis..$^{20}$

\section{GLM}

Green-lipped mussel is another dietary component or supplement associated with improvement in clinical signs of osteoarthritis in dogs and cats. ${ }^{4,6,21,22,53,54}$ Products containing GLM may have chrondromodulatory and anti-inflammatory properties. ${ }^{54,55}$ In a controlled clinical trial, ${ }^{21}$ peak vertical force (a measure of gait analysis that determines the amount of weight placed on each limb) was increased over a 60-day period when a GLM-supplemented diet was fed, compared with results when the same dogs received a commercial (control) diet for 30 days. In a field trial, ${ }^{4}$ effects of adding GLM to the diet were dependent on breed size, with small- and mediumsized dogs having greater signs of improvement in subjectively assessed outcomes than larger dogs, suggesting that the product should be administered on a per-kilogram body weight basis. Dogs and cats that had dietary supplementation with GLM were found to have improvement in arthritis scores, joint swelling, and signs of joint pain. ${ }^{4,6,21,31,53,54}$ Supplements are commercially available for veterinary use, and although recommended dosages have not been clearly established, amounts needed for large patients may be expensive. Green-lipped mussel may be especially useful for arthritic cats and smaller dogs.

\section{Glucosamine and Chondroitin Sulfate}

Glucosamine and chondroitin sulfate are dietary components or supplements that function synergistically; human medical research has shown that glucosamine contributes to cartilage formation and repair, ${ }^{56}$ reduces inflammation, and slows cartilage deterioration $^{57-60}$ and that chondroitin sulfate improves the elastic properties of cartilage ${ }^{56}$ and reduces painful swelling in joints. ${ }^{57-60}$ Glucosamine also decreases signs of pain associated with osteoarthritis in dogs. ${ }^{23}$ In a randomized, double-blinded, positive-controlled study ${ }^{23}$ in which dogs with osteoarthritis received either carprofen or glucosamine and chondroitin sulfate for 70 days, assessment of the animals by veterinarians indicated that by the end of the study period, dogs in both the glucosamine-chondroitin sulfate and carprofen groups had significant subjective improvements in scores for pain, weight bearing, and overall condition, compared with the findings at baseline (prior to the described interventions). However, the 
onset of improvement in signs of osteoarthritis in the glucosamine-chondroitin sulfate group was delayed, compared with results for the carprofen group, suggesting that continuous dietary supplementation at an appropriate dose should be provided and that more time may be needed to observe such benefits.

\section{Clinical Summary}

Osteoarthritis is a prevalent disease and affects substantial proportions of adult dogs and cats, with prevalence increasing with age. ${ }^{2-7}$ Prevalence of osteoarthritis among pets is high and is increasing because of an aging pet population and because overweight and obese pets have a greater risk of the disease. It has been estimated that more than half of dogs and cats in the United States are obese, ${ }^{35}$ which has been defined as having $\geq 20 \%$ excess body fat and a BCS $\geq 7$ of $9 .{ }^{14,33,34}$ Results of investigations ${ }^{41,61}$ that involved Labrador Retrievers suggest that dogs managed to maintain a lean BCS ( 4 to 5/9) can live longer without requiring medications for osteoarthritis and other chronic diseases, compared with dogs that have a BCS of 6 to $7 / 9$. For overweight pets, controlled weight loss (reduction in body weight by $1 \%$ to $2 \%$ / wk) is recommended ${ }^{14}$; a reduction in body weight by as little as $6 \%$ to $9 \%$ has been shown to aid in osteoarthritis management and allow for reduced dose and administration frequency of analgesic medication. ${ }^{4,33}$ When possible, the use of NSAIDs in osteoarthritic patients should be reduced because these drugs may pose short-term health risks and accelerate cartilage degeneration with long-term use. ${ }^{49}$ Rather than focusing on pain relief only, veterinarians should seek a therapeutic approach that may slow disease progression as well as alleviate signs of pain.

After discussing the various diet and dietary supplement options available with clients, veterinarians can make informed decisions to recommend which approaches may be best for the patient and client. Nutritional approaches may be used to enhance joint health in dogs and cats. The easiest and most controlled way for veterinarians and clients to provide nutritional support for dogs and cats with osteoarthritis is typically through feeding therapeutic diets formulated for joint health. These diets may be a more convenient means of dietary supplementation with ingredients recommended to support joint health than administration of individual supplements, which requires remembering to give pills or possibly struggling with the pet to ensure administration. A multimodal approach to therapy is key for management of joint disease, and appropriate nutrition is an important factor that can slow disease progression, decrease signs of pain, and potentially increase an animal's life span. . $^{3,4,6,13,14,17,22,48,62}$

Nutritional management, including weight management and dietary supplementation with products such as glucosamine, chondroitin sulfate, omega- 3 fatty acids, and GLM in appropriate amounts, may increase patient mobility ${ }^{18-21,23}$ and allow for reduced NSAID use. ${ }^{18,62}$ The easiest way for veterinarians and clients to combat the effects of osteoarthritis in pets may be the use of therapeutic diets formulated for joint health, which have been associated with the ability to reduce NSAID dosage in osteoarthritic dogs. ${ }^{18,62}$ By communicating with clients effectively, veterinarians may not only stress the positive impacts that nutrition and maintaining a healthy weight can have on patients with osteoarthritis, but also educate owners on signs of the disease so early detection and treatment are possible.

\section{Acknowledgments}

No third-party funding or support was received in connection with the writing and publication of this manuscript. The authors declare that there were no conflicts of interest.

\section{Footnotes}

a. Stoa Luedtke E, Schmidt C, LaFlamme D. The effect of food bowl size on the amount of food fed to cats (abstr), in Proceedings. 11th Annu Am Assoc Vet Nutr Clin Nutr Res Symp $2011 ; 8$

\section{References}

1. Fritsch D, Allen TA, Dodd CE, et al. Dose-titration effects of fish oil in osteoarthritic dogs. J Vet Intern Med 2010;24:1020-1026.

2. Johnston SA. Osteoarthritis: joint anatomy, physiology, and pathobiology. Vet Clin North Am Small Anim Pract 1997;27:699-723.

3. Roush JK, Dodd CE, Fritsch DA, et al. Multicenter veterinary practice assessment of the effects of omega- 3 fatty acids on osteoarthritis in dogs. J Am Vet Med Assoc 2010;236:59-66.

4. Servet E, Biourge V, Marniquet P. Dietary intervention can improve clinical signs in osteoarthritic dogs. $J$ Nutr 2006;136:1995S-1997S.

5. Bennett D. Joint disease. In: Chandler EA, Thompson DJ, Sutton $\mathrm{JB}$, et al, eds. Canine medicine and therapeutics. Oxford, England: Blackwell Scientific Publications, 1991;249-308.

6. Laflamme DP. Nutritional care for aging cats and dogs. Vet Clin North Am Small Anim Pract 2012;42:769-791.

7. Kerwin SC. Osteoarthritis in cats. Top Companion Anim Med 2010;25:218-223.

8. Clarke SP, Mellor D, Clements DN, et al. Prevalence of radiographic signs of degenerative joint disease in a hospital population of cats. Vet Rec 2005;157:793-799.

9. Lascelles BD, Henry JB III, Brown J, et al. Cross-sectional study of the prevalence of radiographic degenerative joint disease in domesticated cats. Vet Surg 2010;39:535-544.

10. Price AK, de Godoy MRC, Harper TA, et al. Effects of dietary calcium fructoborate supplementation on joint comfort and flexibility and serum inflammatory markers in dogs with osteoarthritis. J Anim Sci 2017;95:2907-2916.

11. Lawler DF, Evans RH, Larson BT, et al. Influence of lifetime food restriction on causes, time, and predictors of death in dogs. J Am Vet Med Assoc 2005;226:225-231.

12. Kealy RD, Lawler DF, Ballam JM, et al. Evaluation of the effect of limited food consumption on radiographic evidence of osteoarthritis in dogs. J Am Vet Med Assoc 2000;217:16781680 .

13. Comblain F, Serisier S, Barthelemy N, et al. Review of dietary supplements for the management of osteoarthritis in dogs in studies from 2004 to 2014.J Vet Pharmacol Ther 2016;39:1-15.

14. Richardson DC, Schoenherr WD, Zicker SC. Nutritional management of osteoarthritis. Vet Clin North Am Small Anim Pract 1997;27:883-911.

15. Impellizeri JA, Tetrick MA, Muir P. Effect of weight reduction on clinical signs of lameness in dogs with hip osteoarthritis. J Am Vet Med Assoc 2000;216:1089-1091. 
16. Lawler DF, Larson BT, Ballam JM, et al. Diet restriction and ageing in the dog: major observations over two decades. $\mathrm{BrJ}$ Nutr 2008;99:793-805.

17. Bauer JE. Therapeutic use of fish oils in companion animals J Am Vet Med Assoc 2011;239:1441-1451.

18. Fritsch DA, Allen TA, Dodd CE, et al. A multicenter study of the effect of dietary supplementation with fish oil omega-3 fatty acids on carprofen dosage in dogs with osteoarthritis. J Am Vet Med Assoc 2010;236:535-539.

19. Roush JK, Cross AR, Renberg WC, et al. Evaluation of the effects of dietary supplementation with fish oil omega-3 fatty acids on weight bearing in dogs with osteoarthritis. J Am Vet Med Assoc 2010;236:67-73.

20. Moreau M, Troncy E, del Castillo JR, et al. Effects of feeding a high omega-3 fatty acids diet in dogs with naturally occurring osteoarthritis. J Anim Pbysiol Anim Nutr (Berl) 2013;97:830-837.

21. Rialland P, Bichot S, Lussier B, et al. Effect of a diet enriched with green-lipped mussel on pain behavior and functioning in dogs with clinical osteoarthritis. Can J Vet Res 2013;77:66-74.

22. Budsberg SC, Bartges JW. Nutrition and osteoarthritis in dogs: does it help? Vet Clin North Am Small Anim Pract 2006;36:1307-1323.

23. McCarthy G, O'Donovan J, Jones B, et al. Randomised double-blind, positive-controlled trial to assess the efficacy of glucosamine/chondroitin sulfate for the treatment of dogs with osteoarthritis. Vet J 2007;174:54-61.

24. Rychel JK. Diagnosis and treatment of osteoarthritis. Top Companion Anim Med 2010;25:20-25.

25. O'Neill DG, Church DB, McGreevy PD, et al. Prevalence of disorders recorded in dogs attending primary-care veterinary practices in England. PLoS One 2014;9:e90501.

26. Duval JM, Budsberg SC, Flo GL, et al. Breed, sex, and body weight as risk factors for rupture of the cranial cruciate ligament in young dogs. J Am Vet Med Assoc 1999;215:811814 .

27. LaFond E, Breur GJ, Austin CC. Breed susceptibility for developmental orthopedic diseases in dogs. J Am Anim Hosp Assoc 2002;38:467-477.

28. Neogi T, Zhang Y. Epidemiology of osteoarthritis. Rbeum Dis Clin North Am 2013;39:1-19.

29. Hays L, Zhang Z, Mateescu RG, et al. Quantitative genetics of secondary hip joint osteoarthritis in a Labrador RetrieverGreyhound pedigree. Am J Vet Res 2007;68:35-41.

30. Boyan BD, Tosi LL, Coutts RD, et al. Addressing the gaps: sex differences in osteoarthritis of the knee. Biol Sex Differ 2013;4:4.

31. Vassalotti G, Musco N, Lombardi P, et al. Nutritional management of search and rescue dogs. J Nutr Sci 2017;6:e44.

32. German AJ. The growing problem of obesity in dogs and cats. J Nutr 2006;136(suppl 7):1940S-1946S.

33. Marshall WG, Hazewinkel HA, Mullen D, et al. The effect of weight loss on lameness in obese dogs with osteoarthritis. Vet Res Commun 2010;34:241-253.

34. Burkholder WJ, Toll PW. Obesity. In: Hand MS, Thatcher CD, Remillard RL, et al, eds. Small animal clinical nutrition. 4th ed. Topeka, Kan: Mark Morris Institute, 2000;404406.

35. Ward E. US Pet obesity rates plateau and nutritional con fusion grows. Available at: static1.squarespace.com/ static/597c71d3e58c621d06830e3f/t/5c86da47c83025a824 d387ae/1552341575308/2018+APOP+Survey+Press+Relea se.pdf. Accessed Feb 11, 2020.

36. Cooper C, Snow S, McAlindon TE, et al. Risk factors for the incidence and progression of radiographic knee osteoarthritis. Arthritis Rbeum 2000;43:995-1000.

37. Baldwin K, Bartges J, Buffington T, et al. AAHA nutritional assessment guidelines for dogs and cats. J Am Anim Hosp Assoc 2010;46:285-296.

38. Laflamme DP. Development and validation of a body condition score system for dogs. Canine Pract 1997;22(4):10-15.

39. Laflamme DP. Development and validation of a body con- dition score system for cats: a clinical tool. Feline Pract 1997;25(5/6):13-18.

40. Kealy RD, Lawler DF, Ballam JM, et al. Five-year longitudinal study on limited food consumption and development of osteoarthritis in coxofemoral joints of dogs. J Am Vet Med Assoc 1997;210:222-225.

41. Kealy RD, Lawler DF, Ballam JM, et al. Effects of diet restriction on life span and age-related changes in dogs. J Am Vet Med Assoc 2002;220:1315-1320.

42. Huck JL, Biery DN, Lawler DF, et al. A longitudinal study of the influence of lifetime food restriction on development of osteoarthritis in the canine elbow. Vet Surg 2009;38:192198.

43. Smith GK, Paster ER, Powers MY, et al. Lifelong diet restriction and radiographic evidence of osteoarthritis of the hip joint in dogs. J Am Vet Med Assoc 2006;229:690-693.

44. Laflamme DP. Companion animals symposium: obesity in dogs and cats: what is wrong with being fat? J Anim Sci 2012;90:1653-1662

45. USDA Agricultural Research Service FoodData Central website. Available at: fdc.nal.usda.gov. Accessed Feb 11, 2020.

46. Chapman M, Woods GRT, Ladha C, et al. An open-label randomised clinical trial to compare the efficacy of dietary caloric restriction and physical activity for weight loss in overweight pet dogs. Vet J 2019;243:65-73.

47. Mlacnik E, Bockstahler BA, Müller M, et al. Effects of calorie restriction and a moderate or intense physiotherapy program for treatment of lameness in overweight dogs with osteoarthritis. J Am Vet Med Assoc 2006;229:1756-1760.

48. Harper TAM. Conservative management of hip dysplasia. Vet Clin North Am Small Anim Pract 2017;47:807-821.

49. Henrotin Y, Sanchez C, Balligand M. Pharmaceutical and nutraceutical management of canine osteoarthritis: present and future perspectives. Vet J 2005;170:113-123.

50. Lascelles BDX, King S, Roe S, et al. Expression and activity of COX-1 and 2 and 5- LOX in joint tissues from dogs with naturally occurring coxofemoral joint osteoarthritis. J Orthop Res 2009;27:1204-1208.

51. Hansen RA, Harris MA, Pluhar GE, et al. Fish oil decreases matrix metalloproteinases in knee synovia of dogs with inflammatory joint disease. J Nutr Biochem 2008;19:101-108.

52. National Research Council. Nutrient requirements of dogs and cats. Washington, DC: National Academies Press, 2006.

53. Lascelles BDX, DePuy V, Thomson A, et al. Evaluation of a therapeutic diet for feline degenerative joint disease. $J$ Vet Intern Med 2010;24:487-495.

54. Bui LM, Bierer TL. Influence of green lipped mussels (Perna canaliculus) in alleviating signs of arthritis in dogs. Vet Ther 2003;4:397-407.

55. Gibson RG, Gibson SL, Conway V, et al. Perna canaliculus in the treatment of arthritis. Practitioner 1980;224:955-960.

56. Anderson MA. Oral chondroprotective agents. Part I. Common compounds. Compend Contin Educ Pract Vet 1999;21:601-609.

57. Jerosch J. Effects of glucosamine and chondroitin sulfate on cartilage metabolism in OA: outlook on other nutrient partners especially omega-3 fatty acids. Int $J$ Rbeumatol 2011;2011:969012.

58. Bucsi L, Poór G. Efficacy and tolerability of oral chondroitin sulfate as a symptomatic slow-acting drug for osteoarthritis (SYSADOA) in the treatment of knee osteoarthritis. Osteoarthritis Cartilage 1998;6(suppl A):31-36.

59. Michel BA, Stucki G, Frey D, et al. Chondroitins 4 and 6 sulphate in osteoarthritis of the knee; a randomized controlled trial. Arthritis Rbeum 2005;52:779-786.

60. Iovu M, Dumais G, duSouich P. Anti-inflammatory activity of chondroitin sulfate. Osteoartbritis Cartilage 2008;16(suppl 3):S14-S18.

61. Larson BT, Lawler DF, Spitznagel EL Jr, et al. Improved glucose tolerance with lifetime diet restriction favorably affects disease and survival in dogs. J Nutr 2003;133:2887-2892.

62. Davies M. Veterinary clinical nutrition: success stories: an overview. Proc Nutr Soc 2016;75:392-397. 